\title{
Prevalence of Childhood Adversities Among Inpatients With Mental Disorders: A Cross-Sectional Study At Neuropsychiatric Referral Hospital in Rwanda
}

Vianney NYIRIMANA ( $\square$ vianney2020@gmail.com )

Butare University Teaching Hospital (CHUB), Huye

Bizoza RUTAKAYILE

Caraes Ndera Neuropsychiatric Hospital, Kigali

Charles MUDENGE

University of Rwanda

Aimable MUSAFILI

University of Rwanda

Cindi CASSADY

Caraes Ndera Neuropsychiatric Hospital, Kigali

Janvier YUBAHWE

Isange Rehabilitation Center, Huye

\section{Research Article}

Keywords: Adverse childhood experiences, toxic stress response, stress response system

Posted Date: August 24th, 2021

DOl: https://doi.org/10.21203/rs.3.rs-701678/v1

License: (c) (i) This work is licensed under a Creative Commons Attribution 4.0 International License.

Read Full License 


\section{Abstract \\ Background}

The world is dealing with a significant socio-economic burden that must be addressed to secure a favourable future.To figure out this problem, there is an urgent need of healthy and well educated adult population to participate effectively in global economy.Indeed, childhood experiences may affect adult health outcome.Responsive caregiving during childhood is associated with good physical and mental health.On the other hand,a strong link was established between Adverse Childhood Experiences (ACEs) and poor adult physical and mental health outcomes. This study assessed the prevalence of ACEs among adult patients with mental disorders admitted to the post-crisis wards at Caraes Ndera Neuropsychiatric Hospital in Kigali, Rwanda.

\section{Methodology :}

This research was developed as a descriptive cross-sectional study that involved a total of 122 patients aged 18 to 64 years.A convenience sampling was used to collect data using the the Adverse Childhood Experiences International Questionnaire (ACE-IQ). Data was analyzed in terms of frequencies and percentages using the Statistical Package for the Social Sciences (SPSS 21.0).

\section{Results}

Initially, 159 participants were invited to join the study, $122(77 \%)$ met the inclusion criteria and voluntarily consented to participate. Of the 122 participants, $43.4 \%$ were female, $61 \%$ were youth, $67.2 \%$ had primary school as the highest level of education and $29.5 \%$ did not work during the last 12 months. Having separated/divorced or deceased parents was the most frequent ACE item with $64.8 \%$ of participants responding affirmatively. Nearly all (98.4\%) participants had at least one ACE and $77.9 \%$ had at least 4 ACEs.

\section{Conclusions}

This study on ACEs in Rwandan adults with mental disorders revealed that $98.4 \%$ had at least one ACE and almost $80 \%$ of the 122 participants had at least 4 ACEs. The findings indicate that there is a significant need to implement interventions necessary for the prevention of ACEs. Such interventions are necessary to mitigate negative effects of ACEs on child development, to increase children's resiliency and to improve future adult physical and mental health outcomes.

\section{Background}


The world is dealing with a significant socio-economic burden that must be addressed to secure a favourable future (Jenkins et al., 2011).To overcome this burden, nations must have healthy and well educated adults; skilled enough to participate effectively in the global economy (O'Donnell \& O'Donnell, 2016).Thus, child rearing should focus on raising children who grow up being loved, protected, healthy and well educated in order to become responsible adults able to understand and address various challenges in life (UNICEF Annual Report 2017 / UNICEF Publications / UNICEF, n.d.).

Responsive caregiving during childhood is associated with good physical and mental health (Johnson et al., 2013). Children with a history of insecure attachment and a lack of love and trust are more likely to experience psychosocial problems,including anti-social behaviours (P. M. Miller et al., 2000). These potential traumatic experiences during childhood are known as adverse childhood experiences (ACEs). ACEs include child abuse and neglect, growing up in a violent community or an unsafe household characterized by domestic violence,having a family member with mental illness, having ajailed family member, experiencing parental separation, or living in a household with drug or alcohol abuse (World Health Organization, 2018).

ACEs may lead to detrimental health outcomes, including physical and mental disorders according to Felitti and other authors (Felitti et al., 1998). The relationship between ACEs and health outcomes is complex.It likely involves both direct physiological damage in terms of disrupted neurodevelopment resulting from unsafe child exposure to stressors as well as indirect effects through adopting risky soothing behaviours as a way of coping with ACEs (Sterling et al., 2018).

The National Scientific Council on the Developing Child has established three different categories of stress responses in early childhood (National Scientific Council on the Developing Child, 2014; Shonkoff, 2010). The positive stress response refers to a mild or moderate activation of the stress response system with the availability of a protective adult who helps the child to be at ease so that he can observe, learn, practice coping mechanisms and gain experience.A tolerable stress response refers to exposure to severe adversity in the hands of a responsive caregiver that helps the child to calm down.And lastly,the toxic stress response refers to exposure to frequent, prolonged or high level of adversities in the absence of a soothing and protective adult (Franke, 2014; Szilagyi, 2012).

The main effect of the toxic stress response during the developmental period is to establish the stress response system as a dysregulated pattern. This dysregulation may affect various systems, including the nervous, immune, hormonal, cardiovascular, respiratory and gastrointestinal systems. It may also induce modifications in the DNA expression(Anda et al., 2006). The toxic stress response may further have intergenerational effects. Individuals with ACEs were found to be more likely engaged in behaviours that might create potential ACEs among their offspring (M. A. Bellis et al., 2014; Renner \& Slack, 2006).

ACEs are common worldwide. Surveys conducted across 23 states in the USA have indicated that approximately $62 \%$ of adults had been exposed to at least one form of ACE while almost $25 \%$ of them had experienced more than three forms of ACEs (Merrick et al., 2018). However, ACEs are unequally distributed between and within countries with the largest proportions found in low- and middle-income 
countries and among socially disadvantaged groups, including ethnic minorities and poorer communities (M. A. Bellis et al., 2014; Health Organization \& Office for Europe, 2013). In these groups, child abuse and neglect have been reported as the most common forms of ACEs and they may be mediated by household challenges including domestic violence, parental drunkenness and drugs or alcohol misuse (Kabiru et al., 2010; Kiburi et al., 2018; Okello et al., 2014; Violence Against Children and Youth Survey Republic of Rwanda Republic of Rwanda, n.d.).

ACEs remain an unaddressed public challenge that communities are faced with, especially in lowresource settings (Ginocchio, 2018). This may be partly due to the lack of information about ACEs, which contributes to a poor understanding of interventions required for ACE prevention (Oh, Jerman, Silvério Marques, et al., 2018). The aim of this study was to determine the prevalence of ACEs among inpatients with mental disorders. It may contribute to increasing data related to ACEs in Rwanda, where little is known regarding early adverse childhood events and their long-term effect on physical and mental health outcomes.

\section{Methods}

\section{Design, population and duration of the study}

This research is a descriptive cross-sectional study to assess the prevalence of childhood adversities among patients with mental disordersduring a four week period of time, from August to September 2019.Patients included in the study were males and females between the ages of 18 and 64 years and had been diagnosed primarily with psychotic, mood and substance-related disorders.All patients aged 18 years and above,receiving inpatient care during the study period and only those who were able and willing to give informed consent, were included in this research.

\section{Setting}

Caraes Ndera Neuropsychiatric Hospital is a national referral hospital for patients with neurologic and psychiatric disorders located in Kigali, Rwanda. It was established by the Congregation of Brothers of Charity in July 1968 and become functional in 1972.It also serves as a teaching hospital for the University of Rwanda and offers a variety of services: psychiatry, neurology, clinical psychology, ergotherapy and physiotherapy.In this hospital, there are two wards for adult patients with critical symptoms and two post-crisis wards for adult patients with remitted symptoms;one for males and another one for females. Patients are transferred from critical wards to post-crisis wards after remission of their symptoms; in order to continue care with psychotherapy and rehabilitation, prepare them to return to their families and to continue outpatient care.

\section{Procedureand ethical consideration}

Ethical clearance for this study was requested and obtained from the Institutional Review Board (IRB) of the University of Rwanda (UR)/College of Medicine Health Sciences (CMHS). We used the convenience 
sampling method to enroll study participants. All participantsreceived a clear explanation about the nature and the purpose of the research project in the language that they understand well; either English or Kinyarwanda.Participation was strictly voluntary and refusal to participate did not affect their treatment or care.A mental status examination was initially conducted on all participants in order to rule out active neuropsychiatric symptoms that could hinder a successful interview. Patients who volunteered to participate signed an informed consent document and completed questionnaires without identifying information.All data collected was used for research purposes only.

\section{Materials and measures}

The ACE-IQ was designedfor individuals aged 18 years and above by the WHO to measure ACEs in all countries (World Health Organization, 2018). It has also been validated to measure ACEs in Nigeria(Kazeem, 2015). The socio-demographic section of the ACE-IQ that captures data on variables such as age, sex, ethnic group, marital status, educational level and employment status,was modified slightly by removing the variable on ethnic groups as it was not applicable to this study population.Items on the ACE-IQ screen for child exposure to physical, emotional and sexual abuse, physical and emotional neglect, household member treated violently, household member with substance abuse, household member with mental illness, incarcerated household member, having separated/divorced or dead parents, peer violence (bullying), community violence and collective violence. The total score is calculated by summing up the number of events the participant was exposed toand it varies from 0 to 13.

\section{Statistical analysis}

Descriptive statistics were used to recapitulate socio-demographic variables and ACEs in terms of frequencies and percentages using the Statistical Package for the Social Sciences (SPSS) version 21.

\section{Results}

\subsection{Sociodemographic characteristics of participants}

A total number of 159 patients were admitted to the post-crisis wards over the period of 4 weeks between August and September 2019. All 159 patients were invited to participate in the study and 122 patients (77\%) gave their consent and filled out questionnaires ; 4 patients ( $2 \%$ ) refused to participate and 33 patients $(21 \%)$ were not able to give consent due to their unstable mental status.

Table 1 displaysthe socio-demographic characteristics of participants: $43.4 \%$ were female, $56.6 \%$ were male and slightly more than half $(51.6 \%)$ were single. The majority $(61 \%)$ of respondents were youth between the ages of 18 and 35 years. The majority of study participants (88.5\%) were Rwandan with $25.4 \%$ coming from the urban area of Kigali city.Regarding the highest level of education, the majority of our participants (67.2\%) did not go beyond primary school. Less than one fifth (19.7\%) had paid jobs and nearly one third (29.5\%) did not work during the last 12 months. 
Table 1

Sociodemographic characteristics of participants

\begin{tabular}{|c|c|c|c|}
\hline Variables & Characteristics & \% \& Freq. & Cumulative \%\& Freq. \\
\hline \multirow[t]{2}{*}{ Gender } & Female & $43.4 \%(53)$ & $43.4 \%(53)$ \\
\hline & Male & $56.6 \%(69)$ & $100 \%(122)$ \\
\hline \multirow[t]{4}{*}{ Marital status } & Single & $36.1 \%(44)$ & $36.1 \%(44)$ \\
\hline & Married & $51.6 \%(63)$ & $87.7 \%(107)$ \\
\hline & Separated/Divorced & $8.2 \%(10)$ & $95.9 \%(117)$ \\
\hline & Widowed & $4.1 \%(5)$ & $100.0 \%(122)$ \\
\hline \multirow[t]{10}{*}{ aGE } & $15-19 *$ & $4.9 \%(6)$ & $4.9 \%(6)$ \\
\hline & $20-24$ & $15.6 \%(19)$ & $20.5 \%(25)$ \\
\hline & $25-29$ & $21.3 \%(26)$ & $41.8 \%(51)$ \\
\hline & $30-34$ & $19.7 \%(24)$ & $61.5 \%(75)$ \\
\hline & $35-39$ & $15.6 \%(19)$ & $77.0 \%(94)$ \\
\hline & $40-44$ & $8.2 \%(10)$ & $85.2 \%(104)$ \\
\hline & $45-49$ & $6.6 \%(8)$ & $91.8 \%(112)$ \\
\hline & $50-54$ & $4.1 \%(5)$ & $95.9 \%(117)$ \\
\hline & $55-59$ & $3.3 \%(4)$ & $99.2 \%(121)$ \\
\hline & $60-64$ & $0.8 \%(1)$ & $100 \%(122)$ \\
\hline \multirow[t]{9}{*}{ Place of birth } & Kigali city & $25.4 \%(31)$ & $25.4 \%(31)$ \\
\hline & Eastern Province & $23.0 \%(28)$ & $48.4 \%(59)$ \\
\hline & Western province & $13.9 \%(17)$ & $62.3 \%(76)$ \\
\hline & Northern province & $13.9 \%(17)$ & $76.2 \%(93)$ \\
\hline & Southern province & $12.3 \%(15)$ & $88.5 \%(108)$ \\
\hline & Uganda & $4.9 \%(6)$ & $93.4 \%(114)$ \\
\hline & RDC & $2.5 \%(3)$ & $95.9 \%(117)$ \\
\hline & Burundi & $1.6 \%(2)$ & $97.5 \%(119)$ \\
\hline & Other countries & $2.5 \%(3)$ & $100.0 \%(122)$ \\
\hline Level of education & No formal schooling & $4.9 \%(6)$ & $4.9 \%(6)$ \\
\hline
\end{tabular}




\begin{tabular}{|c|c|c|c|}
\hline Variables & Characteristics & \% \& Freq. & Cumulative \%\& Freq. \\
\hline & Less than primary scchool & $27.9 \%(35)$ & $32.8 \%(41)$ \\
\hline & Primary school completed & $34.4 \%(42)$ & $67.2 \%(83)$ \\
\hline & High school completed & $26.2 \%(32)$ & $93.4 \%(115)$ \\
\hline & University or college completed & $6.6 \%(8)$ & $100.0 \%(122)$ \\
\hline \multirow[t]{5}{*}{ Work status } & Not employed with inability to work & $29.5 \%(36)$ & $29.5 \%(36)$ \\
\hline & Not employed with ability to work & $42.6 \%(52)$ & $72.1 \%(88)$ \\
\hline & Retired & $1.6 \%(2)$ & $73.7 \%(90)$ \\
\hline & Student & $6.6 \%(8)$ & $80.3 \%(98)$ \\
\hline & Paid employee & $19.7 \%(24)$ & $100.0 \%(122)$ \\
\hline
\end{tabular}

The prevalence of ACEs among inpatients with mental disorders is shown in Tables 2and 3.The ACE item most frequently selected was exposure to separated/divorced or deceased parents $(n=79 ; 64.8 \%)$. The second most frequently reported ACE was emotional abuse $(n=71 ; 58.2 \%)$. Physical abuse was reported by $68(55.7 \%)$ participants.Sixty-five patients (53.3\%) were exposed to collective violence. Sixty-one patients $(50.0 \%)$ experienced emotional neglect.

Exposure to a household member who was treated violently was reported by 60 (49.2\%) patients. Physical neglect was reported by 58 (47.5\%) patients. Fifty-seven (46.7\%) patients have experienced peer violence. Household drug abuse was acknowledged by 50 (41.0\%) patients.

Exposure to community violence was noted by $50(41.0 \%)$ patients. Incarceration of household members was reported by 42 (34.4\%). Having a household member with mental illness was reported by 40 (32.8\%) patients. Sexual abuse was noted by $37(30.3 \%)$ patients and this ACE was 2.4 times higher in female $(45.3 \%)$ than in male patients(18.8\%). 
Table 2

ACEs among participants

\begin{tabular}{|cllll|}
\hline$N^{\circ}$ & ACEs & $\begin{array}{l}\text { Total \%\& } \\
\text { Fequency /122 }\end{array}$ & $\begin{array}{l}\text { \% \&Frequency of } \\
\text { Female/53 }\end{array}$ & $\begin{array}{l}\text { Frequency \& \% of } \\
\text { males/69 }\end{array}$ \\
\hline 1 & $\begin{array}{l}\text { Separated, divorced or } \\
\text { died parents }\end{array}$ & $64.8 \%(79)$ & $73.6 \%(39)$ & $58.0 \%(40)$ \\
\hline 2 & Emotional abuse & $58.2 \%(71)$ & $54.7 \%(29)$ & $60.9 \%(42)$ \\
\hline 3 & Physical abuse & $55.7 \%(68)$ & $58.5 \%(31)$ & $53.6 \%(37)$ \\
\hline 4 & Collective violence & $53.3 \%(65)$ & $58.5 \%(31)$ & $49.3 \%(34)$ \\
\hline 5 & Emotional neglect & $50.0 \%(61)$ & $52.8 \%(28)$ & $47.8 \%(33)$ \\
\hline 6 & $\begin{array}{l}\text { Household member } \\
\text { treated violently }\end{array}$ & $49.2 \%(60)$ & $62.3 \%(33)$ & $39.1 \%(27)$ \\
\hline 7 & Physical neglect & $47.5 \%(58)$ & $52.8 \%(28)$ & $43.5 \%(30)$ \\
\hline 8 & Peer violence & $46.7 \%(57)$ & $37.7 \%(20)$ & $53.6 \%(37)$ \\
\hline 9 & Household drug abuse & $41.0 \%(50)$ & $45.3 \%(24)$ & $37.7 \%(26)$ \\
\hline 10 & Community violence & $41.0 \%(50)$ & $39.6 \%(21)$ & $42.0 \%(29)$ \\
\hline 11 & $\begin{array}{l}\text { Incarceration of household } \\
\text { members }\end{array}$ & $34.4 \%(42)$ & $34.0 \%(18)$ & $34.8 \%(24)$ \\
\hline 12 & Household mental illness & $32.8 \%(40)$ & $30.2 \%(16)$ & $34.8 \%(24)$ \\
\hline 13 & Sexual abuse & $30.3 \%(37)$ & $45.3 \%(24)$ & $18.8 \%(13)$ \\
\hline 3 & AC & & & \\
\hline
\end{tabular}

\subsection{ACE scores among participants}

ACE scores among participants are shown in Table 3.Nearly all (98.4\%) patients with mental disorders including all (100\%) female patients and $97.1 \%$ of male respondents have had at least one ACE. Almost $92 \%$ of respondents have experienced at least 2 ACEs. Eight-six per cent of patients have had at least 3 ACEs. Almost $78 \%$ of patients experienced 4 ACEs and $32.0 \%$ of them reported at least 8 ACEs. 
Table 3

ACE scores among participants

\begin{tabular}{|lllllll|}
\hline $\begin{array}{l}\text { ACEs } \\
\text { score }\end{array}$ & $\begin{array}{l}\text { Frequency } \\
\text { \& total } \\
\% / 122\end{array}$ & $\begin{array}{l}\text { Cumulative } \\
\text { \% and } \\
\text { Freq. }\end{array}$ & $\begin{array}{l}\text { \%\& Freq.for } \\
\text { females/53 }\end{array}$ & $\begin{array}{l}\text { Cumulative \% \& } \\
\text { Freq for } \\
\text { females }\end{array}$ & $\begin{array}{l}\text { \%\&FrEq. } \\
\text { of } \\
\text { males/69 }\end{array}$ & $\begin{array}{l}\text { Cumulative } \% \\
\text { \& FrEq. for } \\
\text { males }\end{array}$ \\
\hline 12 & $2.5 \%(3)$ & $2.5 \%(3)$ & $3.8 \%(2)$ & $3.8 \%(2)$ & $1.4 \%(1)$ & $1.4 \%(1)$ \\
\hline 11 & $4.1 \%(5)$ & $6.6 \%(8)$ & $0.0 \%(0)$ & $3.8 \%(2)$ & $7.2 \%(5)$ & $8.7 \%(6)$ \\
\hline 10 & $9.8 \%(12)$ & $16.4 \%(20)$ & $9.4 \%(5)$ & $13.2 \%(7)$ & $10.1 \%(7)$ & $18.8 \%(13)$ \\
\hline 9 & $9.8 \%(12)$ & $26.2 \%(32)$ & $13.2 \%(7)$ & $26.4 \%(14)$ & $7.2 \%(5)$ & $26.1 \%(18)$ \\
\hline 8 & $5.7 \%(7)$ & $32.0 \%(39)$ & $9.4 \%(5)$ & $35.8 \%(19)$ & $2.9 \%(2)$ & $28.9 \%(20)$ \\
\hline 7 & $11.5 \%(14)$ & $43.4 \%(53)$ & $11.3 \%(6)$ & $47.1 \%(25)$ & $11.6 \%(8)$ & $40.5 \%(28)$ \\
\hline 6 & $13.1 \%(16)$ & $56.6 \%(69)$ & $15.1 \%(8)$ & $62.2 \%(33)$ & $11.6 \%(8)$ & $52.1 \%(36)$ \\
\hline 5 & $8.2 \%(10)$ & $64.8 \%(79)$ & $11.3 \%(6)$ & $73.6 \%(39)$ & $5.8 \%(4)$ & $57.9 \%(40)$ \\
\hline 4 & $13.1 \%(16)$ & $77.9 \%(95)$ & $11.3 \%(6)$ & $84.9 \%(45)$ & $14.5 \%$ & $72.4 \%(50)$ \\
\hline 3 & $8.2 \%(10)$ & $\begin{array}{l}86.1 \% \\
(105)\end{array}$ & $7.5 \%(4)$ & $92.4 \%(49)$ & $8.7 \%(6)$ & $81.1 \%(56)$ \\
\hline 2 & $5.7 \%(7)$ & $\begin{array}{l}91.8 \% \\
(112)\end{array}$ & $5.7 \%(3)$ & $98.1 \%(52)$ & $5.8 \%(4)$ & $86.9 \%(60)$ \\
\hline 1 & $6.6 \%(8)$ & $\begin{array}{l}98.4 \% \\
(120)\end{array}$ & $1.9 \%(1)$ & $100 \%(53)$ & $10.1 \%(7)$ & $97.1 \%(67)$ \\
\hline 0 & $1.6 \%(2)$ & $\begin{array}{l}100 \% \\
(122)\end{array}$ & $0.0 \%(0)$ & $100 \%(53)$ & $2.9 \%(2)$ & $100 \%(69)$ \\
\hline 34 & & & & & & \\
\hline
\end{tabular}

\subsection{Correlations between variables}

The lack of correlation between the patients'ACE score and their level of education as well as with regard to their work status during the past 12 months is indicated in Table 4. The correlation coefficients were $r=$ $-\mathbf{0 . 1 4 3}$ and $r=0.071$ respectively. The $p$ values were $p=\mathbf{0 . 1 1 3}$ and $\mathbf{p}=\mathbf{0 . 4 3 4}$ respectively. The $r$ values are very close to 0 and $p$ values are above $\mathbf{0 . 0 5}$; there is no correlation between above variables.

However, there was a correlation between household challenges and child maltreatment as indicated in Table 4 especially between childhood exposure to household member being treated violently and physical abuse $(r=0.348 ; p=0.000)$; childhood exposure to household member being treated violently and emotional abuse $(r=0.335 ; p=0.000)$; childhood exposure to household member being treated violently and emotional neglect $(r=0.295 ; p=0.001)$; parental divorce or death and physical abuse $(r=0.241 ; p=$ 0.008); parental divorce or death and emotional abuse $(r=0.210, p=0.021)$; parental divorce or death and sexual abuse $(r=0.225 ; p=0.013)$; parental divorce or death and emotional neglect $(r=0.292 ; p=0.001)$; parental divorce or death and physical neglect $(r=0.290 ; p=0.001)$; household mental illness and 
physical abuse $(r=0.201 ; p=0.027)$; household drug or alcohol abuse and physical abuse $(r=0.273 ; p=$ $0.002)$; household drug or alcohol abuse and emotional abuse $(r=0.301 ; p=0.001)$.

Table 4

Correlations between the patients' ACE score and other variables and interrelatedness between ACEs

\begin{tabular}{|c|c|c|c|c|}
\hline$N=122$ Correlation between & & $\begin{array}{l}\text { Pearson } \\
\text { Correlation }\end{array}$ & $\begin{array}{l}P \\
\text { value }\end{array}$ & $\begin{array}{l}\text { Significant } \\
\text { at }\end{array}$ \\
\hline \multirow[t]{2}{*}{ ACE score } & $\begin{array}{l}\text { Level of } \\
\text { education }\end{array}$ & -0.143 & 0.115 & No \\
\hline & Work status & 0.071 & 0.434 & No \\
\hline \multirow{3}{*}{$\begin{array}{l}\text { Household member being treated } \\
\text { violently }\end{array}$} & Physical abuse & 0.348 & 0.000 & 0.01 level \\
\hline & $\begin{array}{l}\text { Emotional } \\
\text { abuse }\end{array}$ & 0.335 & 0.000 & 0.01 level \\
\hline & $\begin{array}{l}\text { Emotional } \\
\text { neglect }\end{array}$ & 0.295 & 0.001 & 0.01 level \\
\hline \multirow[t]{5}{*}{ Parental divorce or death } & Physical abuse & 0.241 & 0.008 & 0.01 level \\
\hline & $\begin{array}{l}\text { Emotional } \\
\text { abuse }\end{array}$ & 0.210 & 0.021 & 0.05 level \\
\hline & Sexual abuse & 0.225 & 0.013 & 0.05 level \\
\hline & $\begin{array}{l}\text { Emotional } \\
\text { neglect }\end{array}$ & 0.292 & 0.001 & 0.01 level \\
\hline & $\begin{array}{l}\text { Physical } \\
\text { neglect }\end{array}$ & 0.290 & 0.001 & 0.01 level \\
\hline Household mental illness & Physical abuse & 0.201 & 0.027 & 0.05 level \\
\hline \multirow[t]{2}{*}{ Household substance abuse } & Physical abuse & 0.273 & 0.002 & 0.01 level \\
\hline & $\begin{array}{l}\text { Emotional } \\
\text { abuse }\end{array}$ & 0.301 & 0.001 & 0.01 level \\
\hline
\end{tabular}

\section{Discussion}

The current study is the first in Rwanda to assess the prevalence of ACEs among patients with mental disorders. Nearly all (98.4\%) patients with mental disorders have had at least one ACE with a prevalence rate significantly higher than the $52 \%$ rate observed in a general population of adults participating in the original ACE study by Felitti at Kaiser Permanente Hospital in San Diego,California,US (Felitti et al., 1998; Norman et al., 2012).Two other studies measuring the prevalence of ACEs respectively,found $85 \%$ of adolescents of a Brazilian birth cohort (Soares et al., 2016) and $62 \%$ of residents of rural regions of Wisconsin (Iniguez \& Stankowski, 2016) experienced at least one ACE.The disparities in the prevalence may be due to different cultural,socio-economic and medical vs.mental health settings. 
Nearly $78 \%$ of the study participants experienced at least 4 ACEs. This finding was significantly higher than those from an ACE study on outpatients with affective disorders in the Netherlands in which $35.6 \%$ of patients reported at least 4 ACEs (van der Feltz-Cornelis et al., 2019). The difference between the two studies may be interpreted in terms of the sociocultural background of developed countries who typically place more emphasis on child protection than in low income country settings (M. A. Bellis et al., 2014; Health Organization \& Office for Europe, 2013). Individuals with 4 or more ACEs are at high risk of developing a multitude of physical conditions and mental disorders which subsequently result in an increase in cost in national health care services (Anda et al., 2006; M. Bellis et al., 2017; Björkenstam et al., 2013; Varese et al., 2012).Study findings by Anda et al., (2006),Björkenstam et al., (2013) and others,underline the importance for medical personnel to enquire about ACEs during every patient's clinical interview.

The most prevalent ACE in our findings were adults (64.8\%) who had experienced separation,divorce or death of parents during their childhood.This finding was higher than $42 \%$ of Brezilian adolescents who reported parental separation and $10.1 \%$ of them reported parental death (Soares et al., 2016). Indeed,50\% of American children will see their parents' divorce (Oren \& Hadomi, 2020). Descriptively, these data provide insight into some households to be at high risk of child maltreatment : a single parent home has been associated with a higher prevalence of child maltreatment, especially child neglect (Afifi et al., 2015).

Interestingly, emotional abuse was experienced by $58.2 \%$ of the current study's participants. These findings are consistent with a study in Singapore that found similar elevated ACE scores in mental health patients (59.1\%) regarding childhood emotional abuse (Devi et al., 2019). On the other hand, less concern has been shown regarding the impact of emotional abuse on future physical and psychological disorders than other ACE types probably due to the common erroneous belief that it is the least damaging form of ACEs. Despite this misperception, previous studies demonstrated the consequences of emotional abuse and significant harmful effects with regard to several mental,physical and behavioral health outcomes in comparison to other ACEs (Liu et al., 2018).

The prevalence of physical abuse varies not only across continents and countries but also across gender. Physical abuse was reported by $55.7 \%$ of study participants. This prevalence was extremely high compared to the general population in which the global prevalence of childhood physical abuse has been estimated at $25 \%$. There is significant variability in the prevalence physical abuse across countries with $12.0 \%$ and $27.0 \%$ for girls and boys respectively in Europe (Moody et al., 2018). However, these findings for the Rwandan inpatient population are similar to those found in other African countries for the general population.In Zimbabwe $64 \%$ of male and $76 \%$ females and in Kenya $66 \%$ of males and $73 \%$ of females respectively experienced physical abuse during childhood (Cui et al., 2018; Moody et al., 2018).

Exposure to collective violence was reported by $53.3 \%$ of patients. This finding was significantly higher than the global review which found that more than $10 \%$ of children are affected by the armed conflicts worldwide.During collective violence, children may experience direct consequences of violence such as 
physical injuries/death, illnesses, disability, exposure to armed conflicts, torture or indirect consequences such as altered physical, emotional and cognitive development, displacement, separation from family, becoming orphaned, having limited access to health care and education, being required to assume adult responsibilities, having a lack of access to basic needs such as foods and water, violation of children's child right and child maltreatment (Kadir et al., 2019).

Exposure to a household member who was treated violently was reported by almost half $(49.2 \%)$ of the study respondents. These findings supported the results of previous research that found the prevalence of IPV in African countries is estimated to be from 26.5-48\% (Taquette et al., 2019). Furthermore, a significant relationship between children's health problems and their exposure to their mother being treated violently has been established.Kajeepeta et al., (2015)\& Roth et al., (2014) found a significant association between childhood exposure to family conflicts and insomnia later in life.Regardless of the degree of exposure to IPV,children growing up in violent homes experience more emotional,behavioural,social and cognitive problems and more symptoms,such as depression,anxiety,conduct disorder and attention deficit hyperactivity disorders (ADHD) than children growing up in nonviolent homes (Rydström et al., 2019)

Bullying was reported by $46.7 \%$ of patients and it was more often reported by male than female patients. This finding was slightly similar to the general population in 40 western countries where the range from $8.6 \%$ to $45.2 \%$ and $4.8 \%$ to $35.8 \%$ among boys and girls respectively experienced bullying (Craig et al., 2009).Researchers have found persuading evidence of interrelatedness between bullying victimization of children and adverse mental, behavioural and physical outcomes later in life. Given the evidence, there is a need for effective actions to be implemented in different institutions caring for children especially at schools where the high prevalence of children and adolescents engaging in bullying has been found (Moore et al., 2017).

Exposure to community violence was noted by $41.0 \%$ of patients. These data fall within the same range of the rates of child exposure to community violence among African American (54.4\%), Hispanic (42.9\%),White (21.8\%) and Asian (21.8\%) youth (Chen et al., 2016). Moreover, witnessing the killing of someone, seeing dead, mutilated bodies and physical attack with weapons have been proven to be the most upsetting traumatic experiences during community violence (Rieder \& Elbert, 2013).

Having a household member with mental illness was reported by $32.8 \%$ of patients. These findings were much higher than the global estimation of $15 \%$ and $23 \%$ of children living with parent with mental illness (Patrick et al., 2019).The literature suggests that mental illness in the household creates a non conducive environment to the optimal development of a child. It is therefore better to detect and treat mental illness during the postnatal period as early as possible.The benefit may be the prevention of harmful consequences such as insecure infant attachment at 2 and 18 months and maladaptive behaviours of the patients including maltreatment of their children (Slomian et al., 2019).

The prevalence of childhood sexual abuse occurs more frequently in girls (25\%) than boys (9\%) worldwide (Evaluation of Sexual Abuse in Children and Adolescents - UpToDate, n.d.). Our findings 
revealed that childhood sexual abuse in psychiatric patients occurred at significantly a higher rate compared to the general population; $45.3 \%$ of female patients and $18.8 \%$ of male patients reported experiencing sexual abuse as a child. Those alarming findings are congruent to the Rwandan survey onViolence Against Children and Youth that almost $24 \%$ of girls and $10 \%$ of boys were victims of sexual abuse (Violence Against Children and Youth Survey Republic of Rwanda Republic of Rwanda, n.d.).Interpretation may refer to children's vulnerability especially in the context ofhousehold challenges.Consistent with this interpretation, girls are vulnerable to sexual abuse but prevention and intervention programs target both genders (Pérez-Fuentes et al., 2013). However, male individuals with history of sexual abuse are more likely to develop psychopathology such as mood disorders and suicidal behaviours than their counterparts (Angelakis et al., 2019; A. B. Miller et al., 2013).

The current research study has revealed the significant burden that ACEs place on a select inpatient psychiatric population in Rwanda.The study demonstrates the negative impact of ACEs on the community as well as on individuals'medical and psychological health (Dube et al., 2009; Norman et al., 2012).Previous studies have found that hospitalization is an important indicator of expensive health care.Furthermore,mental and behavioural disorders are the most common pathologies responsible for hospital readmissions (Anda et al., 2007; Fang et al., 2015; Gryczynski et al., 2016).

The findings of this study did not find a correlation between an ACE score and the participants'level of education and work status during last 12 months. The data may be interpreted in terms of resilience which is defined as the capacity to resist or to overcome the damaging effects of adversity. Some participants have resisted adversities for a long period of time; $6.6 \%$ have completed a university level of education and $19.7 \%$ held paying jobs and were relatively stable in their occupational, social and professional functions before being admitted to the hospital for their symptomatology. Key factors to promote resilience are responsive care giving, fair treatment, good educational experiences, and opportunities to exert valued social roles (M. A. Bellis et al., 2018).

Despite this perspective, the majority of this study population did not achieve a high level of education and $67.2 \%$ did not study beyond the primary school level. They were also economically challenged as $42.6 \%$ of those who could work, were not employed, $29 \%$ were either totally or partially unable to work during the previous 12 months and $1.6 \%$ were retired. These alarming findings highlight the socioeconomic burden for patients with mental disorders. It is true that ACEs may contribute to this problem but further research studies are encouraged in order to delineate other underlying causes.

However, our findings demonstrated a correlation between child maltreatment and different household challenges as noted in the previous studies (Choudhry et al., 2018). This interrelatedness between ACEs suggests that they cannot be regarded as independent events during ACE studies. Anyway, different forms of ACEs share the same interacting factors at different levels: individual, parental, familial and social (Soares et al., 2016).

\section{Limitations}


The results of this study have been interpreted within the context of several possible limitations. The ACEs mentioned in the ACE-IQ are not alone to produce toxic stress response.Other risk factors to toxic stress have been identified in recent studies such as separation from a caregiver in foster care, migration and discrimination (Oh, Jerman, Purewal Boparai, et al., 2018). Additional considerations such as being born with HIV infection, being born from sex worker parents, teenager and unwanted pregnancy may hypothetically be added to the list given the psychopathology associated with those childhood events in Rwanda.

In addition, similar to other studies on ACEs, the retrospective nature and the self-reported data of the ACE-IQ may limit the ability to document all ACEs with precision. This limitation may be due to the possibility of recall error, overestimation or underestimation of those experiences and other retrospective biases.

\section{Conclusions And Recommendations}

This seminal study provides introductory and useful data in advancing our insight on the high prevalence of ACEs in hospitalized patients with mental disorders and the paucity of data on ACEs in Rwanda.Early recognition of ACEs with appropriate interventions can mitigate their negative effects on child development and can lead to better mental and physical health outcomes. If Rwandans had insight into the pernicious effects of ACEs on their mental health,it may empower them to seek preventive mental health care services. This insight may also provide motivation to learn useful parenting skills to help stop the intergenerational cycle of ACE transmission from parents to children.

It is critical to set the stage early for the prevention of ACEs in Rwandan children.Recognition of the lifelong impact of ACEs on normal development of children has been lacking in Rwanda and other developing countries. Identifying and addressing family problems, providing positive parenting programs, Trauma-Informed Care and Trauma-Informed Network of Care, and all interventions that can foster individuals' resiliency have been used in high-income countries with positive outcomes. It is imperative that the healthcare system in Rwanda includes ACE screenings in its general approach to medical healthcare in order to identify children and families at high risk for future mental and physical health problem.

\section{List Of Acronyms And Abbreviations}

ACE-IQ: Adverse Childhood Experiences International Questionnaire

ACEs: Adverse Childhood Experiences

CDC: Center for Disease Control and Prevention

CMHS: College of Medicine Health Sciences 
CPA : Childhood Physical Abuse

CRH: Corticotropin-Releasing Hormone

CSA : Child Sexual Abuse

DNA: Deoxyribonucleic acid

HPA: The Hypothalamic-Pituitary-Adrenal axis

IPV: Intimate Partner Violence

IRB: Institutional Review Board

NPH : Neuropsychiatric Hospital

RDC : Republic Democratic of Congo

SDGs: Sustainable Development Goals

SPSS: Statistical Package for the Social Sciences

UR: University of Rwanda

\section{Declarations}

Ethics approval and consent to participate : Ethical clearance for this study has been requested and obtained from the Institutional Review Board (IRB) of the University of Rwanda (UR)/College of Medicine Health Sciences (CMHS). Written informed consents were given to the participants during the period of data collection. The meaning of the investigation was explained, and their participation was invited anonymously and voluntarily, resulting in a $77 \%$ participation. Subsequently, the questionnaires were distributed on paper. During its completion the main author of the study remained in place with the intention of resolving any doubt or difficulties. All methods were carried out in accordance with the ethical principles for medical research involving human subjects.

Consent for publication : Not applicable.

Availability of data and materials : All data and sensitive information are not publicly available. However, under a reasonable requirement, the data can be shared by writing a request to the following email address: vianney2020@gmail.com

Competing interests : The authors declare that they have no competing interests.

Funding :This study was funded by the authors themselves and the role of the funding body did not interfere in the study design, data collection and analysis neither in th einterpretation of the results. 
Authors' contributions: VN, JY and BR have conceived the study. VN has developed study design, data collection and analysis and interpretation of the findings. JY, BR and AM did study supervision. Drafting of the manuscript was done by VN.Critical revision of themanuscript for important intellectual content was carried out by JY, AM, CM, BR and CC. All authors have approved the final manuscript.

Acknowledgments :We acknowledge Dr Alfred Ngirababyeyi for his assistance with editing the research proposal for this study.We are thankful to Brother Charles NKUBILI, the Director General of Ndera-NPH to allow this study to be conducted in the hospital. We are also grateful to $\mathrm{Mr}$ Jean Baptiste Serugendo for his contribution during data analysis and interpretation.

\section{References}

1. Afifi, T. O., Taillieu, T., Cheung, K., Katz, L. Y., Tonmyr, L., \& Sareen, J. (2015). Substantiated reports of child maltreatment from the Canadian incidence study of reported child abuse and neglect 2008: Examining child and household characteristics and child functional impairment. Canadian Journal of Psychiatry. https://doi.org/10.1177/070674371506000704

2. Anda, R. F., Brown, D. W., Felitti, V. J., Bremner, J. D., Dube, S. R., \& Giles, W. H. (2007). Adverse Childhood Experiences and Prescribed Psychotropic Medications in Adults. American Journal of Preventive Medicine. https://doi.org/10.1016/j.amepre.2007.01.005

3. Anda, R. F., Felitti, V. J., Bremner, J. D., Walker, J. D., Whitfield, C., Perry, B. D., Dube, S. R., \& Giles, W. H. (2006). The enduring effects of abuse and related adverse experiences in childhood: A convergence of evidence from neurobiology and epidemiology. European Archives of Psychiatry and Clinical Neuroscience. https://doi.org/10.1007/s00406-005-0624-4

4. Angelakis, I., Gillespie, E. L., \& Panagioti, M. (2019). Childhood maltreatment and adult suicidality: A comprehensive systematic review with meta-analysis. In Psychological Medicine. https://doi.org/10.1017/S0033291718003823

5. Bellis, M. A., Hughes, K., Ford, K., Hardcastle, K. A., Sharp, C. A., Wood, S., Homolova, L., \& Davies, A. (2018). Adverse childhood experiences and sources of childhood resilience: A retrospective study of their combined relationships with child health and educational attendance. BMC Public Health, 18(1). https://doi.org/10.1186/s12889-018-5699-8

6. Bellis, M. A., Hughes, K., Leckenby, N., Jones, L., Baban, A., Kachaeva, M., Povilaitis, R., Pudule, I., Qirjako, G., Ulukol, B., Raleva, M., \& Terzic, N. (2014). Adverse childhood experiences and associations with health-harming behaviours in young adults: Surveys in eight eastern European countries. Bulletin of the World Health Organization. https://doi.org/10.2471/BLT.13.129247

7. Bellis, M., Hughes, K., Hardcastle, K., Ashton, K., Ford, K., Quigg, Z., \& Davies, A. (2017). The impact of adverse childhood experiences on health service use across the life course using a retrospective cohort study. Journal of Health Services Research and Policy. https://doi.org/10.1177/1355819617706720 
8. Björkenstam, E., Hjern, A., Mittendorfer-Rutz, E., Vinnerljung, B., Hallqvist, J., \& Ljung, R. (2013). MultiExposure and Clustering of Adverse Childhood Experiences, Socioeconomic Differences and Psychotropic Medication in Young Adults. PLOS ONE. https://doi.org/10.1371/journal.pone.0053551

9. Chen, P., Voisin, D. R., \& Jacobson, K. C. (2016). Community Violence Exposure and Adolescent Delinquency: Examining a Spectrum of Promotive Factors. Youth and Society. https://doi.org/10.1177/0044118X13475827

10. Choudhry, V., Dayal, R., Pillai, D., Kalokhe, A. S., Beier, K., \& Patel, V. (2018). Child sexual abuse in India: A systematic review. In PLoS ONE (Vol. 13, Issue 10). https://doi.org/10.1371/journal.pone.0205086

11. Craig, W., Harel-Fisch, Y., Fogel-Grinvald, H., Dostaler, S., Hetland, J., Simons-Morton, B., Molcho, M., de Mato, M. G., Overpeck, M., Due, P., Pickett, W., Molcho, M., Mazur, J., Favresse, D., Leveque, A., Craig, W., Pickett, W., Aasvee, K., Varnai, D., ... Nansel, T. (2009). A cross-national profile of bullying and victimization among adolescents in 40 countries. International Journal of Public Health. https://doi.org/10.1007/s00038-009-5413-9

12. Cui, N., Deatrick, J. A., \& Liu, J. (2018). Maternal and paternal physical abuse: Unique and joint associations with child behavioral problems. Child Abuse and Neglect. https://doi.org/10.1016/j.chiabu.2017.05.003

13. Devi, F., Shahwan, S., Teh, W. L., Sambasivam, R., Zhang, Y. J., Lau, Y. W., Ong, S. H., Fung, D., Gupta, B., Chong, S. A., \& Subramaniam, M. (2019). The prevalence of childhood trauma in psychiatric outpatients. Annals of General Psychiatry. https://doi.org/10.1186/s12991-019-0239-1

14. Dube, S. R., Fairweather, D., Pearson, W. S., Felitti, V. J., Anda, R. F., \& Croft, J. B. (2009). Cumulative childhood stress and autoimmune diseases in adults. Psychosomatic Medicine. https://doi.org/10.1097/PSY.0b013e3181907888

15. Evaluation of sexual abuse in children and adolescents - UpToDate. (n.d.). Retrieved June 3, 2020, from https://www.uptodate.com/contents/evaluation-of-sexual-abuse-in-children-and-adolescents

16. Fang, X., Fry, D. A., Ji, K., Finkelhor, D., Chen, J., Lannen, P., \& Dunne, M. P. (2015). The burden of child maltreatment in China: a systematic review. Bulletin of the World Health Organization. https://doi.org/10.2471/blt.14.140970

17. Felitti, V. J., Anda, R. F., Nordenberg, D., Williamson, D. F., Spitz, A. M., Edwards, V., Koss, M. P., \& Marks, J.S. (1998). Relationship of childhood abuse and household dysfunction to many of the leading causes of death in adults: The adverse childhood experiences (ACE) study. American Journal of Preventive Medicine. https://doi.org/10.1016/S0749-3797(98)00017-8

18. Franke, H. (2014). Toxic Stress: Effects, Prevention and Treatment. Children. https://doi.org/10.3390/children 1030390

19. Ginocchio, B. Y. J. (2018). The Science of Adverse Childhood Experiences, Toxic Stress and Resilience. January.

20. Gryczynski, J., Schwartz, R. P., O’Grady, K. E., Restivo, L., Mitchell, S. G., \& Jaffe, J. H. (2016). Understanding patterns of high-cost health care use across different substance user groups. Health 
Affairs. https://doi.org/10.1377/hlthaff.2015.0618

21. Health Organization, W., \& Office for Europe, R. (2013). European report on preventing child maltreatment World Health Organization Regional Offi ce for Europe. www.euro.who.int

22. Iniguez, K. C., \& Stankowski, R. V. (2016). Adverse childhood experiences and health in adulthood in a rural population-based sample. Clinical Medicine and Research.

https://doi.org/10.3121/cmr.2016.1306

23. Jenkins, R., Baingana, F., Ahmad, R., McDaid, D., \& Atun, R. (2011). Social, economic, human rights and political challenges to global mental health. In Mental Health in Family Medicine.

24. Johnson, S. B., Riley, A. W., Granger, D. A., \& Riis, J. (2013). The science of early life toxic stress for pediatric practice and advocacy. In Pediatrics. https://doi.org/10.1542/peds.2012-0469

25. Kabiru, C. W., Beguy, D., Crichton, J., \& Ezeh, A. C. (2010). Self-reported drunkenness among adolescents in four sub-Saharan African countries: Associations with adverse childhood experiences. Child and Adolescent Psychiatry and Mental Health. https://doi.org/10.1186/1753-2000-4-17

26. Kadir, A., Shenoda, S., \& Goldhagen, J. (2019). Effects of armed conflict on child health and development: A systematic review. In PLOS ONE. https://doi.org/10.1371/journal.pone.0210071

27. Kajeepeta, S., Gelaye, B., Jackson, C. L., \& Williams, M. A. (2015). Adverse childhood experiences are associated with adult sleep disorders: A systematic review. In Sleep Medicine. https://doi.org/10.1016/j.sleep.2014.12.013

28. Kazeem, O. T. (2015). A Validation of the Adverse Childhood Experiences Scale in Nigeria. Online).

29. Kiburi, S. K., Molebatsi, K., Obondo, A., \& Kuria, M. W. (2018). Adverse childhood experiences among patients with substance use disorders at a referral psychiatric hospital in Kenya. BMC Psychiatry. https://doi.org/10.1186/s12888-018-1780-1

30. Liu, R. T., Scopelliti, K. M., Pittman, S. K., \& Zamora, A. S. (2018). Childhood maltreatment and nonsuicidal self-injury: a systematic review and meta-analysis. The Lancet Psychiatry. https://doi.org/10.1016/S2215-0366(17)30469-8

31. Merrick, M. T., Ford, D. C., Ports, K. A., \& Guinn, A. S. (2018). Prevalence of Adverse Childhood Experiences from the 2011-2014 Behavioral Risk Factor Surveillance System in 23 States. JAMA Pediatrics, 172(11). https://doi.org/10.1001/jamapediatrics.2018.2537

32. Miller, A. B., Esposito-Smythers, C., Weismoore, J. T., \& Renshaw, K. D. (2013). The Relation Between Child Maltreatment and Adolescent Suicidal Behavior: A Systematic Review and Critical Examination of the Literature. In Clinical Child and Family Psychology Review. https://doi.org/10.1007/s10567013-0131-5

33. Miller, P. M., Gorski, P. A., Borchers, D. A., Jenista, J. A., Johnson, C. D., Kaufman, N. D., Levitzky, S. E., Palmer, S. D., Poole, J. M., Rezin, J., Hablutzel, N., Huggins, M., Kanda, M. B., Spahr, P., Stubbs-Wynn, P., Murph, J. R., \& Casey, E. (2000). Developmental issues for young children in foster care: Committee on early childhood, adoption and dependent care. In Pediatrics (Vol. 106, Issue 5 I, pp. 1145-1150). American Academy of Pediatrics. https://doi.org/10.1542/peds.106.5.1145 
34. Moody, G., Cannings-John, R., Hood, K., Kemp, A., \& Robling, M. (2018). Establishing the international prevalence of self-reported child maltreatment: A systematic review by maltreatment type and gender. In BMC Public Health. https://doi.org/10.1186/s12889-018-6044-y

35. Moore, S. E., Norman, R. E., Suetani, S., Thomas, H. J., Sly, P. D., \& Scott, J. G. (2017). Consequences of bullying victimization in childhood and adolescence: A systematic review and meta-analysis. World Journal of Psychiatry. https://doi.org/10.5498/wjp.v7.i1.60

36. National Scientific Council on the Developing Child. (2014). Excessive Stress Disrupts the Architecture of the Developing Brain: Working Paper 3. Working Papers. https://doi.org/10.1111/j.1151-2916.1918.tb17232.x

37. Norman, R. E., Byambaa, M., De, R., Butchart, A., Scott, J., \& Vos, T. (2012). The Long-Term Health Consequences of Child Physical Abuse, Emotional Abuse, and Neglect: A Systematic Review and Meta-Analysis. In PLoS Medicine. https://doi.org/10.1371/journal.pmed.1001349

38. O’Donnell, K., \& O'Donnell, M. L. (2016). Global Mental Health: sharing and synthesizing knowledge for sustainable development. Global Mental Health. https://doi.org/10.1017/gmh.2016.22

39. Oh, D. L., Jerman, P., Purewal Boparai, S. K., Koita, K., Briner, S., Bucci, M., \& Harris, N. B. (2018). Review of Tools for Measuring Exposure to Adversity in Children and Adolescents. Journal of Pediatric Health Care. https://doi.org/10.1016/j.pedhc.2018.04.021

40. Oh, D. L., Jerman, P., Silvério Marques, S., Koita, K., Purewal Boparai, S. K., Burke Harris, N., \& Bucci, M. (2018). Systematic review of pediatric health outcomes associated with childhood adversity. BMC Pediatrics, 18(1). https://doi.org/10.1186/s12887-018-1037-7

41. Okello, J., De Schryver, M., Musisi, S., Broekaert, E., \& Derluyn, I. (2014). Differential roles of childhood adversities and stressful war experiences in the development of mental health symptoms in post-war adolescents in northern Uganda. https://doi.org/10.1186/s12888-014-0260-5

42. Oren, D., \& Hadomi, E. (2020). Let's Talk Divorce - An Innovative Way of Dealing with the Long-Term Effects of Divorce through Parent-Child Relationships. Journal of Divorce and Remarriage. https://doi.org/10.1080/10502556.2019.1679593

43. Patrick, P. M., Reupert, A. E., \& McLean, L. A. (2019). A cross-sectional study on intergenerational parenting and attachment patterns in adult children of parents with mental illness. Child and Family Social Work. https://doi.org/10.1111/cfs.12641

44. Pérez-Fuentes, G., Olfson, M., Villegas, L., Morcillo, C., Wang, S., \& Blanco, C. (2013). Prevalence and correlates of child sexual abuse: A national study. Comprehensive Psychiatry. https://doi.org/10.1016/j.comppsych.2012.05.010

45. Renner, L. M., \& Slack, K. S. (2006). Intimate partner violence and child maltreatment: Understanding intra- and intergenerational connections. Child Abuse and Neglect.

https://doi.org/10.1016/j.chiabu.2005.12.005

46. Rieder, H., \& Elbert, T. (2013). Rwanda - Lasting imprints of a genocide: Trauma, mental health and psychosocial conditions in survivors, former prisoners and their children. Conflict and Health. https://doi.org/10.1186/1752-1505-7-6 
47. Roth, M., Neuner, F., \& Elbert, T. (2014). Transgenerational consequences of PTSD: Risk factors for the mental health of children whose mothers have been exposed to the Rwandan genocide. International Journal of Mental Health Systems. https://doi.org/10.1186/1752-4458-8-12

48. Rydström, L.-L., Edhborg, M., Ring Jakobsson, L., Nahar Kabir, Z., \& Byass, P. (2019). Global Health Action Young witnesses of intimate partner violence: screening and intervention Young witnesses of intimate partner violence: screening and intervention. https://doi.org/10.1080/16549716.2019.1638054

49. Shonkoff, J. P. (2010). Building a new biodevelopmental framework to guide the future of early childhood policy. In Child Development. https://doi.org/10.1111/j.1467-8624.2009.01399.x

50. Slomian, J., Honvo, G., Emonts, P., Reginster, J. Y., \& Bruyère, O. (2019). Consequences of maternal postpartum depression: A systematic review of maternal and infant outcomes. In Women's Health. https://doi.org/10.1177/1745506519844044

51. Soares, A. L. G., Howe, L. D., Matijasevich, A., Wehrmeister, F. C., Menezes, A. M. B., \& Gonçalves, H. (2016). Adverse childhood experiences: Prevalence and related factors in adolescents of a Brazilian birth cohort. Child Abuse and Neglect, 51, 21-30. https://doi.org/10.1016/j.chiabu.2015.11.017

52. Sterling, S., Chi, F., Weisner, C., Grant, R., Pruzansky, A., Bui, S., Madvig, P., \& Pearl, R. (2018). Association of behavioral health factors and social determinants of health with high and persistently high healthcare costs. Preventive Medicine Reports. https://doi.org/10.1016/j.pmedr.2018.06.017

53. Szilagyi, M. (2012). The pediatric role in the care of children in foster and kinship care. Pediatrics in Review. https://doi.org/10.1542/pir.33-11-496

54. Taquette, S. R., Leite, D., \& Monteiro, M. (2019). Causes and consequences of adolescent dating violence: a systematic review KEY WORDS Dating violence Gender Adolescence Exposure toviolence. J Inj Violence Res. https://doi.org/10.5249/jivr.v11i2.1061

55. UNICEF Annual Report 2017 / UNICEF Publications / UNICEF. (n.d.). Retrieved June 3, 2020, from https://www.unicef.org/publications/index_102899.html

56. van der Feltz-Cornelis, C. M., Potters, E. C., van Dam, A., Koorndijk, R. P. M., Elfeddali, I., \& van Eck van der Sluijs, J. F. (2019). Adverse Childhood Experiences (ACE) in outpatients with anxiety and depressive disorders and their association with psychiatric and somatic comorbidity and revictimization. Cross-sectional observational study. Journal of Affective Disorders. https://doi.org/10.1016/j.jad.2018.12.096

57. Varese, F., Smeets, F., Drukker, M., Lieverse, R., Lataster, T., Viechtbauer, W., Read, J., Van Os, J., \& Bentall, R. P. (2012). Childhood adversities increase the risk of psychosis: A meta-analysis of patientcontrol, prospective-and cross-sectional cohort studies. Schizophrenia Bulletin. https://doi.org/10.1093/schbul/sbs050

58. Violence Against Children and Youth Survey Republic of Rwanda Republic of Rwanda. (n.d.). Retrieved June 16, 2020, from

59. World Health Organization. (2018). Adverse Childhood Experiences International Questionnaire. Adverse Childhood Experiences International Questionnaire (ACE-IQ). 